University of Nebraska - Lincoln

DigitalCommons@University of Nebraska - Lincoln

7-1997

\title{
The World as a Multilevel Mosaic: Understanding Regions
}

Robert Stoddard

University of Nebraska - Lincoln, rstoddard1@unl.edu

Follow this and additional works at: https://digitalcommons.unl.edu/geographyfacpub

Part of the Geography Commons

Stoddard, Robert, "The World as a Multilevel Mosaic: Understanding Regions" (1997). Geography Faculty Publications. 5.

https://digitalcommons.unl.edu/geographyfacpub/5

This Article is brought to you for free and open access by the Geography Program (SNR) at DigitalCommons@University of Nebraska - Lincoln. It has been accepted for inclusion in Geography Faculty Publications by an authorized administrator of DigitalCommons@University of Nebraska - Lincoln. 


\title{
The World as a Multilevel Mosaic: Understanding Regions
}

\author{
Robert H., Stoddard \\ Department of Geography, University of Nebraska-Lincoln
}

The geographically informed person knows and understands that people create regions to interpret Earth's complexity.Geography for Life: National Geography Standards 1994 (Geographic Educational Standards Project, 1994)

$\mathbf{T}$ he teacher who strives to help students in their understanding and appreciation of geography inevitably must confront the concept of regions. A region, as explained in the Geography for Life 1994 (Geographic Educational Standards Project 1994, 7071) is:

a concept that is used to identify and organize areas of Earth's surface for various purposes. A region has certain characteristics that give it a measure of cohesiveness and distinctiveness and that set it apart from other regions. As worlds within worlds, regions can be used to simplify the whole by organizing Earth's surface on the basis of the presence or absence of selected physical and human characteristics. As a result, regions are human constructs whose boundaries and characteristics are derived from sets of specific criteria. They can vary in scale from local to global; overlap or be mutually exclusive; exhaus- tively partition the entire world or capture only selected portions of it. They can nest within one another, forming a multilevel mosaic Understanding the idea of region and the process of regionalization is fundamental to being geographically informed.

In this article, I want to expand on "the idea of region." By considering several aspects of regions and regionalization, a teacher is able to help students comprehend this concept that plays such a critical role in our view of the world.

The goal of classification is to simplify a complex multitude of individuals/objects by grouping them into fairly homogeneous classes, and the goal of regionalization is to simplify the infinite variation of places by grouping relatively similar ones into regions. The resulting classes and regions then affect the way we see differences among phenomena and places.

Regions, like classes, are normally identified by the phenomenon that is categorized, such as soil regions, crop regions, and family income regions. If several criteria are used to regionalize an area, the identifying terms may be more comprehensive, as illustrated by those called climatic, political, and socioeconomic regions.

The type of region discussed here is a political one because area units are the results of dividing the Earth's surface into sovereign territories, that is, countries. The focus is on the way humans organize themselves spatially (i.e., geographically) into regional units. Although the state is not always the most suitable entity for examining human activities, it is convenient for gathering data and for organizing information. Furthermore, because nationalism is such a dominant force in the world today, many events are understood best by considering the actions of states rather than by considering other groupings of humans. I wish to emphasize the concept of regionalization and its importance in comprehending how we think about our world.

\section{The Nature of Political Regions}

The regions of the world that form countries contrast with those regions that are defined for only scholastic purposes (e.g., the Mediterranean-type climatic region) or used in common communication (e.g., the Midwest, as a perceived region). Those other regions normally have imprecise boundaries and do not carry any regulatory importance. Most political regions, 
however, are expressed as areas with well-defined boundaries and are associated with specific jurisdictional control.

The degree to which political regions - or administrative units - affect humans, of course, varies with the level of government. At the local level, living in one territory rather than another may only regulate the amount of taxes paid, the quality of fire and police protection, the type of school available, and similar regulatory and service conditions. At the international level, however, the division of the Earth's surface into regions, each defining the territory of a state, has tremendous effects.

This was not always so. Several centuries ago, before the establishment of modern states, many people identified with a group on the basis of kinship or a similar nonterritorial relationship. Now, however, virtually everyone in the world is regarded as a citizen of a particular state and subject to all the rights and obligations of that state, which is sometimes called "nation-state." Citizenship is usually, but not always, based on where each person was born or lives. Whether one was born on one side of a national boundary or a few meters on the other side has innumerable social, economic, and political implications for that person's life.

To be born and live in a sovereign state is to be under its absolute jurisdiction. The state can control what resources may be used for food, clothing, and housing. It can determine what medical and educational services are available to its citizens. It can regulate where a person may travel. It may even restrict what citizens can express publicly.

States do more than just control resources and people; they are also a powerful force in engendering group identity. It is impossible to describe all the innumerable manifestations of nationalism in the world today: but, to illustrate the emotional and political expressions of being affiliated with a country, note a couple events familiar to most Americans. When a few individuals who were citizens of the United States were held hostage in the foreign country of Iran, the media attention was intense and prolonged, and the situation affected governmental politics and policies. At another time, the U.S. government declared that harming a few of its citizens in Panama was adequate justification for military intervention. In contrast, thousands of other human beings in the world who were in danger of being killed (for example, in Rwanda) were ignored by the media in the United States because they are not defined as U.S. citizens. To be a citizen of a particular state, therefore, has tremendous implications; and, to repeat, citizenship is usually based on the territorial division of the Earth.

Group identity does not always coincide with the jurisdictional boundaries of the state or other political units; there are also perceptual regions that separate "us and our land" from "them and their territory." This view of "we" versus "they" is fundamental to understanding the political attitudes and events of the world. It essentially says that "we" belong together, will share the costs and responsibilities for our well-being, and expect to gain full benefits emanating from such cooperation, and that "they" belong somewhere else and should not interfere in our lives.

The number of individuals within "our" group varies with the degree of sharing. In American society, maintaining a common purse/account is usually restricted to just the immediate family members. At this level, all members benefit from food and lodging, even small children and elderly family members who do not earn any income. Usually members live in the same household and thus are in the same geographical place, but belonging to the family group is not contingent on being spatially close together.

At a different level or degree of sharing. the support of an education system entails apportioning the costs and benefits within a larger group, which may vary from a few families in a rural school district to an entire state that collects and allocates tax revenues to all its districts. Belonging to the group is expressed by a policy of taxing all income earners, irrespective of whether they attend school or not, and letting all children, even those who have not individually paid taxes, gain an education. At the country level, citizens often provide for, and benefit from, transportation facilities, emergency assistance, and military forces. For all of these, "our" group and "their" group are defined by political regions.

What are the prospects that the current international division of the world will change in the near future? If boundaries between countries are altered, that directly and immediately affects the lives of all persons living in those areas that become part of a different territorial unit. Politically, those changes are implied by the question: What governmental body makes decisions about what group of people? If we phrase the question geographically, it becomes the following: Where should the boundaries of an autonomous population be located?

Initially, the issue might be regarded as only a question of state size. How small a region is suitable for constituting a country? One the size of Singapore, which is 580 square kilometers (234 sq. mi.)? One the size of Grenada, which has a population of 100,000 ? One the size of the immediate vicinity around Sarajevo? One the size of an ethnic district in a large metropolis like Toronto or New York City or Bombay? Or should the suitable size be such that it would result in a world of several thousand smaller, but more homogeneous, countries than those that exist now?

At the other extreme, how big a region encompassing how much ethnic diversity is reasonable? The former Soviet Union covered a sixth of the Earth's land surfaceface. China comprises a fifth of the 
world's population. The size of the European Community? The size of the former Yugoslavia? The size of Sri Lanka or Cyprus?

As implied by the examples, the critical element is not size per se; rather, it is the composition and outlook of the people residing within an area that affect their satisfaction with the existing state boundaries. Dissatisfaction with the current regionalization of the world is being expressed in two somewhat contradictory trends: one toward the splintering of existing countries of the world into smaller political regions and the other toward uniting states into larger units.

\section{The Trend toward Smaller States}

The boundaries of the current countries of the world result from a complex history of many rather arbitrary political agreements, often based on conquests or other circumstances unique to a particular time. For example, the boundaries of many states in Africa established by European colonial powers during the Berlin Conference of 1884 sometimes cut through ethnic and cultural regions and often encompassed dissimilar peoples, thus assigning them to multiethnic states. Irrespective of their illogical origins, those boundaries persist today and carry all the prestige and power of sovereignty. The protracted civil war in the Sudan, for example, illustrates the conflict between groups: one wanting to retain the boundaries of the existing state and the other fighting for new political units that will create more cultural homogeneity.

Another system of regions of the world consists of groups of peoples, each composed of persons who share a common culture, often including a language, religion, and history. Although the terminology applied to such groups is confusing, they are often regarded as nations. In most parts of the world, members of each nation have occupied a particular territory for hundreds of years, have developed a strong sense of attachment to that land, and believe that the area belongs to them. The belief in a national homelanda perceived region-contributes to what is called regionalism.

Although some national groups have occupied the same land for more than a thousand years, others may have a shorter history. In places where people have moved from one place to another-by forced or voluntary migration and as conquering or invaded populations - mixtures of national groups often occur. If, at some later date, one national group views the members of another as outsiders, attempts to push out members of a group may result. When such a campaign occurs at the state level, persons of the persecuted groups, even those who were born in and have lived all their lives in the state, are viewed as "foreigners."

Whereas the territories of states have internationally recognized boundaries, the areas considered by national groups as their homeland are imprecisely defined and are often not delimited. Furthermore, these two sets of regions do not match. In contrast to the fewer than 200 countries of the world, there are an estimated 5,000 nations. This lack of coincidence between the official boundaries of countries and $t$ he regions of perceived nationhood is the driving force for the many civil wars and other conflicts involving ethno-regionalism.

Ethno-regional conflicts have attracted considerable world attention in recent years. This increased concern may result from a variety of circumstances, ranging from a growing awareness by previously isolated people about the potential for their empowerment, to the tremendous expansion of global economic forces that have an impact on distant places. Whatever the specific causes, it is apparent that the forces of nationalism and ethnoregionalism are challenging the existing delineation of countries and that there are strong pressures for dividing many of the existing countries into smaller, more homogeneous political units.

As an illustration of ethno-regionalism, consider the situation in Sri Lanka. Because the countries of the world recognize the absolute sovereignty of Sri Lanka, the government in Colombo insists that it bears the entire responsibility for maintaining civil order and for punishing those individuals who violate the laws of the state. Furthermore, the government in Colombo is considered to be the legitimate expression of the people's will because it was elected by a popular vote.

However, the situation appears differently to many of the people ethnically defined as "Sri Lankan Tamils." In the nation-region of the Sri Lankan Tamils, the majority of the people insist that they have experienced considerable discrimination from, and have been persecuted by, the dominant government. From the perspective of the Sri I Lankan Tamils, they should be recognized as citizens of a new nation-state (Tamil Eelam) in which they are responsible for their own regulation of law and order.

Resistance to such a division comes not only from the established government and the majority of voters in Sri Lanka but also from other governments of the world that do not want to disturb the status quo. They contend that any encouragement given to secessionist groups will lead to a massive splintering of states, and such a process of subdividing existing states has no logical end. That is, even if all of today's civil wars were solved by forming new, independent states, it would not satisfy all the demands for self-rule. To continue the Sri Lankan example, the acceptance of a new country of Tamil Eelam would not necessarily solve all the ethnic conflicts on that island. What if most of the Muslim population in a new country of Tamil Eelam elected to secede and form yet another independent country? And 




Figure 1. North Africa and Southwest Asia: Physiography

Lowest elevation: The Dead Sea, on the border of Israel and Jordan, is 1,302 feet (397 meters) below sea level.

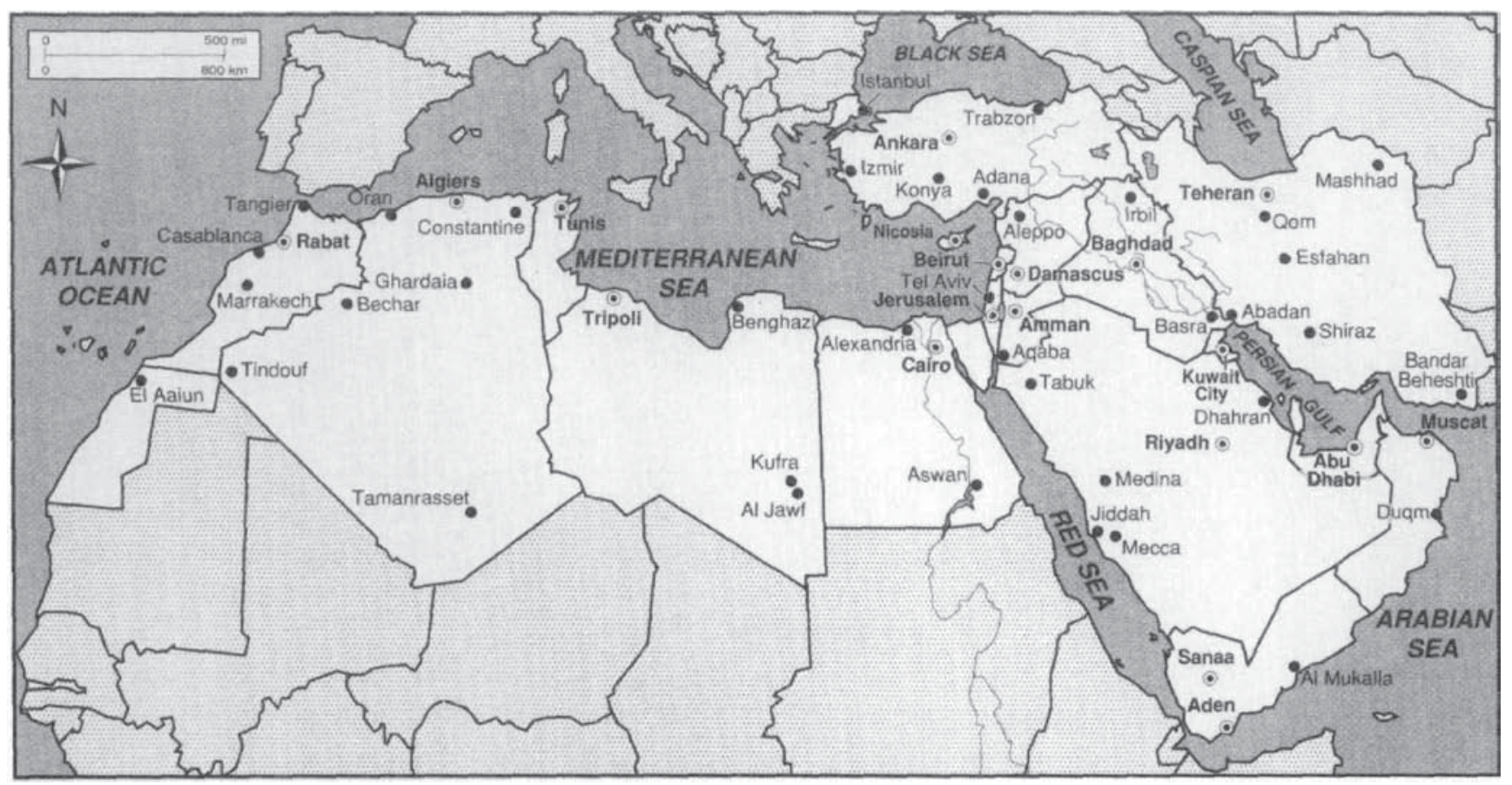

North Africa and Southwest Asia: Major Cities.

Reprinted with permission from GEOGRAPHY ON FILETM (c) 1993 Facts On File, Inc. 
if that happened, would this new Muslim-defined nation-state then experience subsequent demands from its minorities for further political divisions?

\section{The Trend toward Larger Political Units}

While numerous national groups seek the subdivision of some existing states, other factors promote the organization of humans into larger regions of governance. Economic, environmental, and political forces can encourage a change toward the creation of larger regions.

Today powerful forces, seeking a more integrated global economy, are encouraging the combination of states into trading unions and similar political entities that create large economic regions. The development of the European Community, which evolved from various regional trading unions, was driven largely by the desire to reduce the constraining effects of boundaries on the movement of goods, labor, and capital. Likewise, NAFTA (the North American Free Trade Association) came into existence primarily because several businesses wanted access to markets larger than those provided by only a single country. Companies selling television programs, electronic services, and other forms of mass communication prefer to operate in a world without restrictive boundaries.

Those who are concerned about environmental conditions often advocate greater political cooperation because most natural phenomena function independently from boundaries drawn by humans. Regulating the type and kind of particulates in the air, the amount of ozone-depleting gases, and the quality and quantity of surface and ground waters depends on international cooperation. Agreements designed to reduce harmful emissions into the air or curtail water pollution, even though usually sponsored by the United Nations, still must be signed by individual sovereign states. If a country refuses to sign such an agreement or to meet its standards, the entire world may suffer the consequences. Dissatisfaction with such an outcome provides the rationale for establishing governmental entities with greater regional coverage.

A motivation for larger political regions arises from the desire to control international drug and crime organizations. Law enforcement agencies in numerous countries are frequently frustrated by international boundaries that restrict their pursuit of criminals and drug operators who operate globally. This situation creates the demand for one or a few superstate judicial organizations having the power to enforce laws throughout a larger portion of the world than the existing individual states.

Another reason that people in one part of the world are advocating involvement in the affairs of "foreign" governments is concern for what many declare are basic human rights. People throughout the world learn about-and see on their television screens - the effects of human beings deprived of the basic necessities of food and housing, denied judicial compensation, imprisoned and tortured, and killed. Such inhuman treatment is regarded as more than just a local matter; it is viewed as affecting the world community and needing to come under the jurisdiction of international governance. Whether these inhuman acts result from the lack of a central control over paramilitary bands and small gangs (such as in Somalia), a dictatorial overthrow of a democratically elected government (illustrated by Haiti), or an ethnic war (as in the former Yugoslavia), the plea from several world leaders is for international intervention.

\section{Summary}

The geographic concern with the organization of area involves the concept of regions and regionalization - the spatial division of Earth's surface into homogeneous classes. Because regions provide a construct that helps in comprehending the complex variations in the world, they are an essential teaching element. Regions are already used, of course, in everyday classroom conversations in such terms as "the play area," "the school zone" "the downtown," and "the countryside"; but regional terms are helpful also in conveying information about "New England" and "the rainforest."

Although the boundaries of the play area or the rainforest are seldom exact, the terms are still useful in expressing generalizations. In contrast, most political regions are precisely defined because governmental units have legally delineated boundaries. Even though political regions and their boundaries are well demarcated, they are not necessarily permanent. Changes have occurred throughout history, and boundaries encompassing states will undoubtedly continue to be modified.

On the one hand, many ethnic groups yearn for greater autonomy over what they regard as their own affairs. Each perceives "its own" group as fairly homogeneous in language, religion, or other cultural characteristics, and wants political independence and self-government. The division of former Czechoslovakia into two countries and the break-up of the former Soviet Union into fifteen illustrate this force. If this becomes a dominant trend, the world will consist eventually of several hundred nations.

On the other hand, other forces seek a reduction in the role of those boundaries separating some or all states. The European Community, NAFTA, and similar trade unions 
demonstrate the desire to reduce the economic effects of national boundaries. Similarly, international agreements designed to regulate world pollution levels, fishing quotas, and crime syndicates necessarily diminish the impact of boundaries separating individual states. Recent attempts by the United Nations and other multinational bodies to ameliorate the persecution of ethnic groups within particular countries also illustrate a diminution of total state sovereignty.

Any change causes numerous repercussions. Consequently, some people oppose any decisions that challenge the sovereignty of existing, recognized nation-states. Usually the issue underlying conflicts over whether or not to change the political map concerns who belongs together. Because membership in political entities is defined territorially, the question is essentially one of regionalization. In other words, controversies arise from the way regions are perceived and delimited. The concept of regions as ways of thinking about the categorization of space and the delineation of an area can be presented at various scales and levels of background. That concept might be achieved at the elementary level, for example, by having students mark off "the play area" and other classroom "regions" and the having them describe appropriate behavior in each region. At the secondary level, a teaching activity might commence with students attempting to map their perceptions of "districts" in a city and then discussing the implications of such perceived regions.

Teachers can help students understand that people construct regions to interpret Earth's complexity. Mastering that concept is essential because understanding the idea of region and the process of regionalization is fundamental to being geographically informed.

\section{Reference}

Geographic Educational Standards Project 1994. Geography for Life: National Geography Standards 1994. Washington D.C.: National Geographic Society. 